\title{
Transitions between care settings after enrolment in a palliative care service in Italy: a retrospective analysis
}

\author{
Daniela D’Angelo, Mastroianni Chiara, Ercole Vellone, Rosaria Alvaro, Giuseppe Casale, \\ Lucatelli Stefania, Roberto Latina, Maria Matarese, Maria Grazia De Marinis
}

\begin{abstract}
This study was a retrospective analysis of prospectively collected data that aimed to map patients' care transitions following admission to a specialist palliative care service in Italy called Antea Centre. Patients' data was extracted from the Antea local database from 2007 to $201 \mathrm{I}$. External transitions were defined as a change in the setting of care, with the patient no longer being cared for by Antea staff. Internal transitions were defined as a change in the setting of care, with the care still being provided by Antea staff. A total of I 123 patients out of 5313 admitted to the palliative service $(21 \%)$ experienced transitions. Patients who experienced no transitions after their admission to the palliative care service were more likely to have a Karnofsky Performance Scale Index $\leq 30$, to have been referred by a hospital physician, to have a shorter survival time, and to have home as their place of death $(P<0.001)$. Although the patients with no transitions had worse clinical conditions, organisations should pay attention to reducing the possible negative effects of transitions, such as discontinuity of care and poor coordination.

Key words: Palliative care Terminal care Care setting transitions - Continuity of patient care
\end{abstract}

DD is Registered Nurse and $\mathrm{PhD}$ student, EV is Assistant Professor, and RA is Associate Professor, School of Nursing, Tor Vergata University, Rome, Italy; MC is Registered Nurse and $\mathrm{PhD}$ student, $\mathbf{G C}$ is Medical Director, and LS is Palliative Care Program Manager, Antea Centre, Rome,

Italy; RL is Registered

Nurse and PhD student, School of Public Health, La Sapienza University, Rome, Italy; $\mathbf{M M}$ is an Assistant Professor, and MGD is an Associate Professor, School of Nursing, University Campus Bio-Medico, Rome, Italy

Correspondence to: Daniela D'Angelo d.angelo@med. uniroma2.ituniroma2.it the patient and the caregiver must make the effort to redefine relationships, create new communication channels, reformulate objectives, and reconstruct a climate of trust (Norton et al, 1997).

Transitions between care settings may be characterised as movements within clinical contexts between different organisations (e.g. hospital, home care, long-term care), between different clinical contexts within the same organisation (e.g. different wards in the same hospital), or between different types of care within the same health-care service (e.g. home care or residential palliative care) (Duggleby and Berry, 2005). The supply of different types of care in response to the changing needs and desires of patients and their families represents a typical characteristic of palliative care services, which are recognised not so much as single physical locations (hospice, nursing home, etc) but as assistance networks that are able to interface and integrate (Bomba, 2005). People who require palliative care may experience numerous transitions (National Institutes of Heath, 2004), and their high level of vulnerability means that these transitions deserve particular attention (Ronaldson and Devery, 2001; Duggleby and Berry, 2005). They require careful planning, coordination, and efficacious communication between the staff and the institutions involved. Various studies have highlighted the relationships between deficiencies in these required aspects of care, compromised continuity of care (Sahlberg-Blom et al, 1998; Soelver et al, 2012), and a decreasing level of safety, comfort, and general wellbeing for patients and their family members (Hauser, 2009; Marsella, 2009; Abarshi et al, 2010). The nursing community is closely involved in the transitions of people at the end of life, with a key role in facilitating communication and coordination between different providers and different settings.

In Italy, notable investments by the government since 2000 (Decreto del Presidente del Consiglio dei Ministri 20, 2000) have raised palliative care services to the point where there are now around 200 hospices in the country (Zucco, 2010). As a 
consequence, an ever-increasing number of patients have the possibility of being cared for by a multidisciplinary palliative care team that is able to give assistance in different settings, such as hospices, day hospices, and in the home. Various studies (Beccaro et al, 2007; Mercadante and Vitrano, 2010) have tried to comprehend the evolution of these new services-e.g. by studying their distribution and number, means of access, and the survival of the patients they care for. However, to the authors' knowledge, no study has focused on the transitions between different care settings experienced by patients in Italy following their admission to a palliative care service. Considering that such transitions may be traumatic both for patients and their families, some of the reasons for trying to understand these phenomena are that increased knowledge may help to reduce unnecessary changes, to predict care needs, to guide the interaction with different health-care providers, and to enhance the use of different settings (Coleman and Boult, 2003; Chalmers and Coleman, 2006).

\section{Aim}

This study represented the first attempt to describe and analyse transitions in an Italian palliative care service, with particular reference to the dimensions of the phenomenon, the types of transitions carried out, and the presence of differences between those who experienced transitions and those who did not.

\section{Methodology}

This was a retrospective analysis in which the sample comprised the people admitted to a palliative care service in Lazio, called Antea Centre, between 2007 and 2011. This palliative care service started in 1987 and since 1999 (after opening the first regional hospice) has become a point of reference in the Lazio region in implementing a palliative care network. At present it covers the territories of the province of Rome and assists more than 1500 patients per year, offering integrated services such as telemedicine, nursing home care, day hospice, and inpatient hospice. Antea Centre receives funds from a combination of the health authorities, private subjects, and a non-profit local charity institution. It offers multidisciplinary care for the dying with a team consisting of physicians, nurses, social workers, physiotherapists, spiritual care staff, and volunteers.

\section{Data collection}

Patient data was extracted from the Antea database, Argos, which is a local system for input and recovery of health information coming from clinical records. This database is considered to be valid and reliable, especially because its program contains various checks to reduce missing information, and only qualified personnel with the appropriate password have access to it. The information extracted from Argos related to patients' gender, age, diagnosis, source of referral, care setting, Karnofsky Performance Scale (KPS) (Yates et al, 1980) at admission, any transitions carried out during enrolment in the palliative care service, place of death, length of survival (only for those who underwent no transitions or only internal transitions), and period of stay in the structure (only for those who underwent external transitions).

For the purpose of the study, internal transitions were defined as any change in the care setting within the palliative services provided by Antea Centre. External transitions were any change in the care setting outside the palliative services provided by Antea Centre.

\section{Ethical considerations}

This study was approved on 30 November 2011 by the ethical review board of Antea Centre. To preserve confidentiality all patient information was provided anonymously.

\section{Statistical analysis}

Descriptive statistics were used to describe the patient characteristics and the dimensions of the transitions phenomenon. Inferential statistics used included chi-square and contingency tables or the t-test, where appropriate, to make between-group comparisons. SPSS 13.0 for Windows was used to analyse the data.

\section{Results}

Within the 5 years of the study, 5320 patients were enroled in Antea Centre. The majority of these $(95 \%)$ had a diagnosis of cancer and they had a mean age of 74 years (standard deviation (SD) 12 years), a predominance of KPS indexes between 30 and 40 (88\%), and a mean survival time within Antea Centre of 39 days (Table 1).

Of these 5320 patients, 1123 (21\%) experienced at least one transition. There were significant differences between the group of patients who did not undergo any transition and the group who had at least one transition. The patients who did not experience any transition were significantly more likely to have a KPS index $\leq 30$ $(74.1 \%$ vs $60.6 \%, P<0.01)$, to have been referred by a hospital physician $(42.6 \%$ vs $35.9 \%, P<0.01$ ), and to have had a diagnosis of lung cancer $(23.6 \%$ vs $17.9 \%, P<0.01)$ (Table 2$)$.

'Transitions
due to
unexpected
exacerbations
of pathology
or to the
tendencies of
clinicians to
conceive of
their field of
activity and
responsibility
as limited to a
distinct
working area
make it
difficult to
carry out
coordinated
and continuous
care ...

-Transitions

due to

unexpected

exacerbations

of pathology

or to the

tendencies of

clinicians to

conceive of

their field of

activity and

responsibility

as limited to a

distinct

working area

make it

difficult to

carry out

coordinated

care ...? 
Table I. Patient characteristics $(n=5320)$

\begin{tabular}{|c|c|}
\hline Characteristic & Number \\
\hline Gender male & $2674(50.2 \%)$ \\
\hline Gender female & $2646(49.7 \%)$ \\
\hline Age $0-25$ & $19(0.3 \%)$ \\
\hline Age 26-5I & $28 \mathrm{I}(5.3 \%)$ \\
\hline Age $52-77$ & $2643(49.7 \%)$ \\
\hline Age $78-103$ & $2377(44.7 \%)$ \\
\hline Diagnosis of lung cancer & $|20|(22.6 \%)$ \\
\hline ... colorectal cancer & $663(12.5 \%)$ \\
\hline ... urinary tract cancer & $649(12.2 \%)$ \\
\hline ... breast cancer & $402(7.6 \%)$ \\
\hline ... pancreatic cancer & $476(8.9 \%)$ \\
\hline ... upper $\mathrm{Gl}$ tract cancer & $374(7.0 \%)$ \\
\hline ... female genital tract cancer & $250(4.7 \%)$ \\
\hline ... leukemia/lymphoma & $127(2.4 \%)$ \\
\hline ... other cancer & $904(17.0 \%)$ \\
\hline ... no cancer & $274(5.2 \%)$ \\
\hline Karnofsky score 10 & $37(0.6 \%)$ \\
\hline Karnofsky score 20 & $423(7.9 \%)$ \\
\hline Karnofsky score 30 & $3339(62.7 \%)$ \\
\hline Karnofsky score 40 & $|42|(26.7 \%)$ \\
\hline Karnofsky score 50 & $100(1.8 \%)$ \\
\hline Mean length of survival (days) & 38.8 (SD 52.4) \\
\hline Median length of survival (days) & 21 \\
\hline GP referral & $2854(53.6 \%)$ \\
\hline Hospital physician referral & 2014 (37.9\%) \\
\hline Source of referral unknown & $452(8.4 \%)$ \\
\hline
\end{tabular}

Table 2. Comparison of characteristics of those patients with no transitions and those with at least one transition

\begin{tabular}{|c|c|c|c|}
\hline Characteristic & $\begin{array}{l}\text { Number } \\
\text { (no transition) } \\
(n=4197 ; 78.9 \%)\end{array}$ & $\begin{array}{l}\text { Number } \\
\text { (transition) } \\
(n=\mid 123 ; 21.1 \%)\end{array}$ & $P$-value \\
\hline Diagnosis of lung cancer & 999 (23.6\%) & $202(17.9 \%)$ & $P<0.01$ \\
\hline ... colon-rectum cancer & $526(12.5 \%)$ & $137(12.1 \%)$ & \\
\hline$\ldots$ urinary tract cancer & $498(11.5 \%)$ & $251(22.3 \%)$ & $P<0.0$ I \\
\hline ... breast cancer & $311(7.4 \%)$ & $91(8.1 \%)$ & \\
\hline ...pancreas cancer & $371(8.8 \%)$ & $105(9.3 \%)$ & \\
\hline ... upper $\mathrm{Gl}$ tract cancer & $292(7 \%)$ & $82(7.3 \%)$ & \\
\hline ... female genital tract cancer & 197 (4.7\%) & $53(4.7 \%)$ & \\
\hline ... leukemia/lymphoma & $101(2.4 \%)$ & $26(2.3 \%)$ & \\
\hline ... other cancer & $700(16.7 \%)$ & $204(18.1 \%)$ & \\
\hline ... no cancer & $202(4.8 \%)$ & $72(6.4 \%)$ & \\
\hline Karnofsky score $\leq 30$ & $3119(74.1 \%)$ & $683(60.6 \%)$ & $P<0.01$ \\
\hline Karnofsky score $>30$ & $1014(25.7 \%)$ & 407 (39.2\%) & $P<0.01$ \\
\hline GP referral & $2410(57.4 \%)$ & $720(64.1 \%)$ & $P<0.01$ \\
\hline Hospital physician referral & $1787(42.6 \%)$ & $403(35.9 \%)$ & $P<0.01$ \\
\hline
\end{tabular}

They were significantly less likely to have had a diagnosis of urinary tract cancer.

A total of 671 patients (12.6\%) experienced at least one internal transition in the palliative care service. The median length of survival of the patients who did not have any transition (17 days; interquartile range (IQR) 32) was significantly shorter than that of the patients who had at least one internal transition (58 days; IQR 85) (Table 3). There were also significant differences $(P<0.01)$ between the places of death for these groups. For those who did not experience transitions, the admission setting by definition corresponded to the place of death in all cases.

Table 4 compares the length of survival of these two patient groups. Mean and median length of survival for both those with no transition and those with at least one internal transition were higher for patients $>65$ years of age, patients of the female sex, and patients who were referred by a GP $(P<0.01)$.

External transitions were experienced by 452 patients $(8.5 \%)$. The reason for the transition was mainly hospitalisation in another structure, unsuitability of the current facility for palliative care, or patient refusal of palliative care (Table 5).

\section{Discussion}

The proportion of patients who underwent at least one transition $(21 \%)$ was low compared with a similar study that analysed the care setting transitions experienced by patients after enrolment in a palliative care service, in which $72 \%$ of patients had at least one transition (Burge et al, 2005; Lawson et al, 2006). This could have been due to the shorter mean length of survival found in the present study: 39 days vs 100 days in the study reported in Burge et al (2005) and Lawson et al (2006). This short survival time was expected, as Costantini et al (1999) previously reported a mean survivial period of 38 days for patients enroled in an Italian hospice service. Access to palliative care programmes in Italy is free of charge, so this late referral might suggest poor acceptance of palliative care in Italy generally or among health-care providers (Costantini et al, 1999). Another explanation for the difference between the findings of the present study and others could be due to differences in sampling methods. For example, Abarshi et al (2010) investigated the number of patients who experienced transitions in the last 3 months of life, rather than following enrolment in a palliative care service, and found that $67 \%$ of their sample experienced a transition.

The differences reported here in the KPS index, length of survival, and place of death between 


\begin{tabular}{|c|c|c|c|}
\hline Characteristic & $\begin{array}{l}\text { Number (no transition) } \\
(n=4197 ; 78.9 \%)\end{array}$ & $\begin{array}{l}\text { Number (internal transition) } \\
(n=67|;| 2.6 \%)\end{array}$ & $P$-value \\
\hline Survival $0-25$ days & $2619(62.4 \%)$ & $156(23.2 \%)$ & \\
\hline Survival $26-51$ days & $888(21.1 \%)$ & $150(22.3 \%)$ & \\
\hline Survival $52-77$ days & $303(7.2 \%)$ & $106(15.7 \%)$ & \\
\hline Survival 78-103 days & $167(3.9 \%)$ & $75(11.1 \%)$ & \\
\hline Survival $>103$ days & $220(5.2 \%)$ & $184(27.4 \%)$ & \\
\hline Mean survival (days) & 31.3 (SD 42) & 84 (SD 78) & \\
\hline Median survival (days) & 17 & 58 & $P<0.01$ \\
\hline Place of care at admission: home & $3240(77.1 \%)$ & $563(84 \%)$ & \\
\hline Place of care at admission: hospice & $957(22.8 \%)$ & $108(16 \%)$ & $P=0.10$ \\
\hline Place of death: home & $3240(77.1 \%)$ & 301 (44.9\%) & \\
\hline Place of death: hospice & $957(22.8 \%)$ & $370(55.1 \%)$ & $P<0.01$ \\
\hline
\end{tabular}

Table 4. Length of survival of those patients with no transitions and those with at least one internal transition

\begin{tabular}{|c|c|c|c|c|c|c|}
\hline \multirow[b]{2}{*}{ Characteristic } & \multicolumn{3}{|l|}{ No transitions } & \multicolumn{3}{|c|}{ Internal transition } \\
\hline & $\begin{array}{l}\text { Mean } \\
\text { survival (days) }\end{array}$ & $\begin{array}{l}\text { Median } \\
\text { survival (days) }\end{array}$ & $P$-value & $\begin{array}{l}\text { Mean } \\
\text { survival (days) }\end{array}$ & $\begin{array}{l}\text { Median } \\
\text { survival (days) }\end{array}$ & $P$-value \\
\hline Age $<65$ years & 26 & 15 & & 69 & 45 & \\
\hline Age $\geq 65$ years & 32 & 18 & $P<0.001$ & 87 & 62 & $P<0.05$ \\
\hline Gender male & 29 & 16 & & 78 & 53 & \\
\hline Gender female & 33 & 18 & $P<0.01$ & 91 & 66 & $P<0.05$ \\
\hline GP referral & 41.7 & 23 & & 91 & 71 & \\
\hline Hospital physician referral & 35.4 & 17 & $P<0.001$ & 80 & 53 & $P<0.01$ \\
\hline
\end{tabular}

those who had transitions and those who did not are analogous to the results of the study reported in Burge et al (2005) and Lawson et al (2006). This suggests that patients who do not have transitions have poorer clinical status that does not allow them to be transferred.

Taking length of survival as a timing index regarding the referral of terminally ill patients to palliative care (Costantini et al, 1999), the results of the present study seem to indicate that GPs are more sensitive to the option of palliative care than hospital physicians, and that there is a link between earlier referral and the female sex. Similar findings have also been reported elsewhere (Lamont and Christakis, 2002; Ahmed et al, 2004; Cheng et al, 2005; Osta et al, 2008). However, the higher survival rate for patients $>65$ years of age found in the present study contrasts with other results that link earlier referral to palliative care with younger age (Ahmed et al, 2004; Cheng et al, 2005; Osta et al, 2008). This, along with the average age of the patients in the present study
Table 5. Reasons for external transitions $(n=452 ; 8.5 \%)$

\begin{tabular}{ll} 
Reason & Number \\
\hline Hospital admission & $282(62.4 \%)$ \\
\hline Refusal of palliative care & $130(28.8 \%)$ \\
\hline Unsuitability for palliative care & $40(8.8 \%)$ \\
\hline
\end{tabular}

being 74 years, could be linked to a reported problem of Italian clinicians refusing to abandon curative treatment of younger patients (Beccaro et al, 2007; Mercadante and Vitrano, 2010). For example, it may be easier to decide to move older patients into palliative care because of the difficulties they would face with aggressive curative treatments.

The place of death of the patients who did not experience transitions corresponded to the admission setting. Of the patients who experienced transitions, $262(39 \%)$ died in a different setting from that of their admission. This pattern could be due to these patients being recipients 


'The task of
the care team
is to reduce
unnecessary
transitions
and to give
communication
support when
transitions are
necessary,
along with
sharing patient
care and
empowerment
plans with
family
members...9

of 'respite care' (Carlson et al, 2007; Zucco, 2010; Empeño et al, 2011), a type of assistance supplied by hospices in which the patient is admitted for a given period of time in order to temporarily relieve their family of their caregiving duties. This type of assistance favours respite provision within the organisation already caring for the patient, i.e. internal transition. Various studies have shown that there is a close relationship between the level of backup supplied to caregivers by palliative care teams and the likelihood of achieving a home death, as inpatient admission may be avoided (Tang and McCorkle, 2001; Brazil et al, 2002; Waldrop et al, 2005; Benini et al, 2011).

That $62.4 \%$ of the 452 patients who experienced an external transition were moved to a hospital reflects the need to supply an integrated model of palliative care that takes into consideration other care sectors and areas and that is able to follow patients and their needs over time. External transitions risk interrupting services and providing irregular care simply because they are connected with movement to different organisations and settings. The task of the care team is to reduce unnecessary transitions and to give communication support when transitions are necessary, along with sharing patient care and empowerment plans with family members (Coleman, 2003; Coleman et al, 2005).

In summary, the population that experienced transitions (particularly internal transitions) tended to be healthier, with longer survival and a higher KPS index, but tended to leave their homes and die in a hospice. These particular patients need much attention in order to understand the appropriateness of such late transitions. In general, the population that experiences transitions needs attention because transitions could have negative impacts, such as discontinuity of care and poor coordination.

\section{Limitations}

The study sample came from only one centre and thus may not be considered representative of patients admitted to all Italian palliative care services. Future studies should be multi-centre, with more scrupulous sampling. Second, this study did not evaluate the information relating to patients who experienced external transitions, such as their survival rate and place of admission after discharge. Despite these limitations, the results may be informative for other countries that have similar service provision to Italy. They represent a step on the road to recognising current gaps in continuity of care for patients with advanced illnesses.

\section{Conclusions}

This study analysed the care transitions experienced by patients after enrolment in a palliative care service and has helped to improve our understanding of such phenomena. Further investigation is necessary to better understand why such transitions take place; their number, length, and locations (from and to); and their impact on patients' and caregivers' experiences. Through increased knowledge we may be able to plan clinical interventions to reduce unnecessary transitions and to prevent their possible negative effects. IIPN

\section{Acknowledgments}

The authors wish to thank Antea Centre for its assistance in data collection and support for this study. We are also grateful to Jonathan Murphy for the English translation of the manuscript.

Abarshi E, Echteld M, Van den Block L, Donker G, Deliens L, Onwuteaka-Philipsen B (2010) Transitions between care settings at the end of life in The Netherlands: results from a nationwide study. Palliat Med 24(2): 166-74

Ahmed N, Bestall JC, Ahmedzai SH, Payne SA, Clark D, Noble B (2004) Systematic review of the problems and issues of accessing specialist palliative care by patients, carers and health and social care professionals. Palliat Med 18(6): 525-42

Beccaro M, Costantini M, Merlo DF (2007) Inequity in the provision of and access to palliative care for cancer patients. Results from the Italian survey of the dying of cancer (ISDOC). BMC Public Health 7: 66

Benini F, Fabris M, Pace DS et al (2011) Awareness, understanding and attitudes of Italians regarding palliative care. Ann Ist Super Sanità 47(3): 253-9

Bomba PA (2005) Enabling the transition to hospice through effective palliative care. Case Manager 16(1): 48-52

Brazil K, Bedard M, Willison K (2002) Factors associated with home death for individuals who receive home support services: a retrospective cohort study. BMC Palliat Care 1(1): 2

Burge FI, Lawson B, Critchley P, Maxwell D (2005) Transitions in care during the end of life: changes experienced following enrolment in a comprehensive palliative care program. BMC Palliat Care 4(1): 3

Carlson MD, Morrison RS, Holford TR, Bradley EH (2007) Hospice care: what services do patients and their families receive? Health Serv Res 42(4): 1672-90

Chalmers SA, Coleman EA (2006) Transitional care in later life: improve the move. Generations 30(3): 86-8

Cheng WW, Willey J, Palmer JL, Zhang T, Bruera E (2005) Interval between palliative care referral and death among patients treated at a comprehensive cancer center. J Palliat Med 8(5): 1025-32

Coleman EA, Boult C (2003) Improving the quality of transitional care for persons with complex care needs. J Am Geriatr Soc 51(4): 556-7

Coleman EA (2003) Falling through the cracks: challenges and opportunities for improving transitional care for persons with continuous complex care needs. J Am Geriatr Soc 51(4): 549-55

Coleman EA, Mahoney E, Parry C (2005) Assessing the quality of preparation for posthospital care from the patient's perspective: the care transitions measure. Med Care 43(3): 246-55

Costantini M, Toscani F, Gallucci M et al (1999) Terminal cancer patients and timing of referral to palliative care: a multicenter prospective cohort study. I Pain Symptom 
Manage 18(4): 243-52

Duggleby W, Berry P (2005) Transitions and shifting goals of care for palliative patients and their families. Clin $J$ Oncol Nurs 9(4): 425-8

Decreto del Presidente del Consiglio dei Ministri 20 (2000) Atto di indirizzo e coordinamento recante requisiti strutturali, tecnologici ed organizzativi minimi per i centri residenziali di cure palliative. Gazzetta Ufficiale 21 Marzo Empeño J, Raming NT, Irwin SA, Nelesen RA, Lloyd LS (2011) The hospice caregiver support project: providing support to reduce caregiver stress. J Palliat Med 14(5): 593-7

Hauser JM (2009) Lost in transition: the ethics of the palliative care handoff. J Pain Symptom Manage 37(5): 930-3

Lamont EB, Christakis NA (2002) Physician factors in the timing of cancer patient referral to hospice palliative care. Cancer 94(10): 2733-7

Lawson B, Burge FI, Critchley P, McIntyre P (2006) Factors associated with multiple transitions in care during the end of life following enrollment in a comprehensive palliative care program. BMC Palliat Care 5: 4

Marsella A (2009) Exploring the literature surrounding the transition into palliative care: a scoping review. Int J Palliat Nurs 15(4): 186-9

Mercadante S, Vitrano V (2010) Palliative care in Italy: problem areas emerging from the literature. Minerva Anestesiol 76(12): 1060-71

National Institutes of Health (2004) NIH State-of-theScience Conference Statement on Improving End-of-Life Care. NIH Consens State Sci Statements 21(3): 1-26

Norton PG, Dunn EV, Soberman L (1997) What factors affect quality of care? Using the Peer Assessment Program in Ontario family practices. Can Fam Physician 43: $1739-44$

Osta BE, Palmer JL, Paraskevopoulos T et al (2008) Interval between first palliative care consult and death in patients diagnosed with advanced cancer at a comprehensive cancer center. J Palliat Med 11(1): 51-7

Ronaldson S, Devery K (2001) The experience of transition to palliative care services: perspectives of patients and nurses. Int J Palliat Nurs 7(4): 171-7

Sahlberg-Blom E, Ternestedt BM, Johansson JE (1998) The last month of life: continuity, care site and place of death. Palliat Med 12(4): 287-96

Schumacher KL, Meleis AI (1994) Transitions: a centra concept in nursing. Image J Nurs Sch 26(2): 119-27

Soelver L, Oestergaard B, Rydahl-Hansen S, Wagner L (2012) Advanced cancer patients' self-assessed physical and emotional problems on admission and discharge from hospital general wards--a questionnaire study. Eur J Cancer Care (Engl) 21(5): 667-76

Tang ST, McCorkle R (2001) Determinants of place of death for terminal cancer patients. Cancer Invest 19(2): 165-80

Waldrop DP, Kramer BJ, Skretny JA, Milch RA, Finn W (2005) Final transitions: family caregiving at the end of life. J Palliat Med 8(3): 623-38

Yates JW, Chalmer B, McKegney FP (1980) Evaluation of patients with advanced cancer using the Karnofsky performance status. Cancer 45(8): 2220-4

Zucco F (2010) Hospice in Italia, Seconda Rilevazione Ufficiale. 2nd edn. Medica Editoria e Diffusione Scientifica, Milano

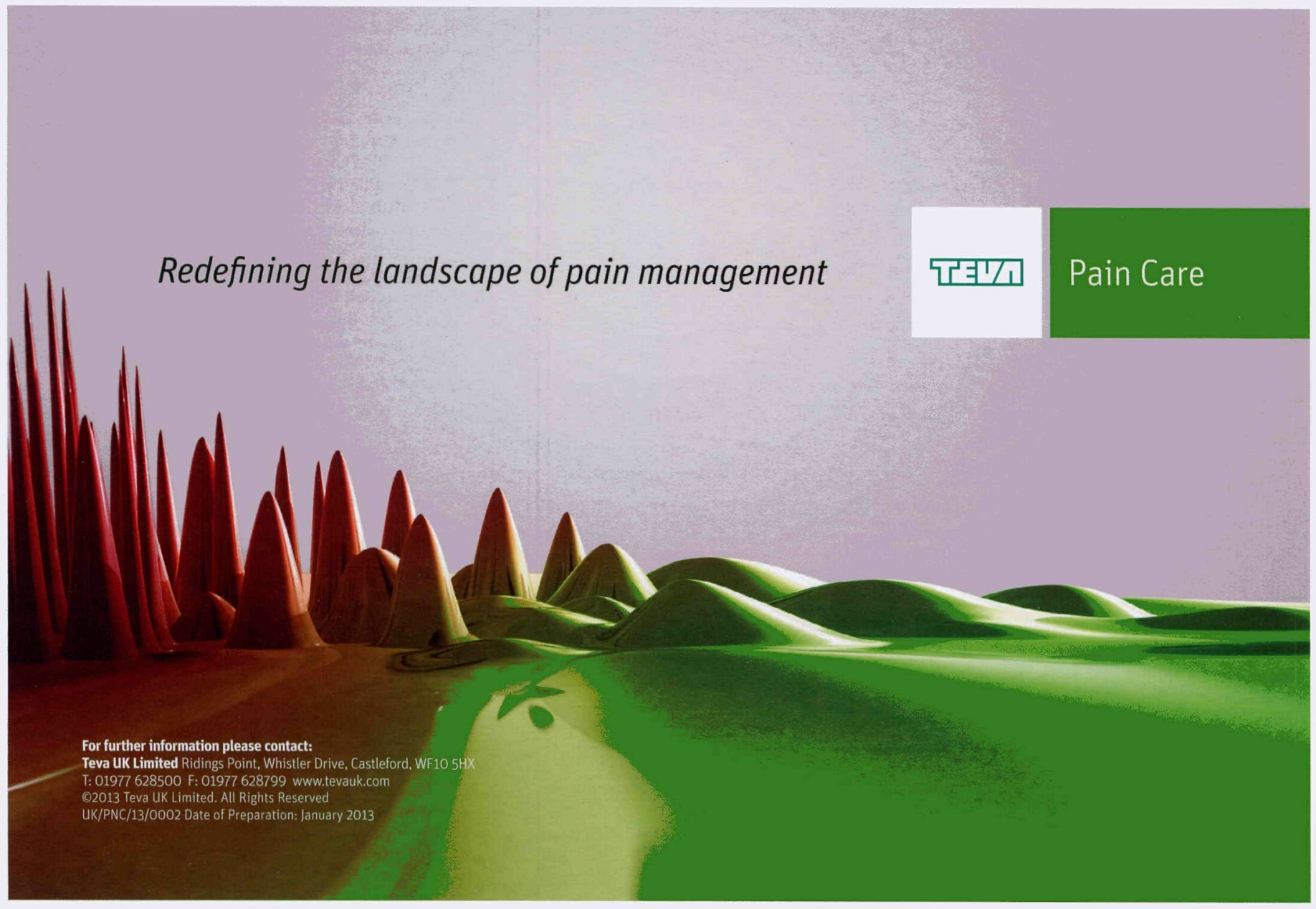


Copyright of International Journal of Palliative Nursing is the property of Mark Allen Publishing Ltd and its content may not be copied or emailed to multiple sites or posted to a listserv without the copyright holder's express written permission. However, users may print, download, or email articles for individual use. 